\title{
DISEÑO DE ESTRATEGIAS DE POSICIONAMIENTO COMO APORTE EN LA INSERCIÓN LABORAL DE LOS GRADUADOS DE LA CARRERA DE TURISMO DE LA UNIVERSIDAD ESTATAL AMAZÓNICA, PERÍODO 2009-2016 DEVELOPMENT OF POSITIONING STRATEGIES FOR LABOR INSERTION OF TOURISM GRADUATES PERIOD 2009-2016 OF UNIVERSIDAD ESTATAL AMAZÓNICA
}

Mario Barrera Castro, Mgtr. Universidad Estatal Amazónica, Puyo, Ecuador. jbarrera8689@gmail.com

Lineth Fernández Sánchez, Ph.D.

(D) https://orcid.org/0000-0002-5986-9750 Universidad Estatal Amazónica, Puyo, Ecuador. lineth1805@gmail.com

David Sancho Aguilera, Ph.D. https://orcid.org/0000-0001-5625-4198 Universidad Estatal Amazónica, Puyo, Ecuador. dsanch01972@gmail.com

Carolina Heras Heras, Mgtr. Universidad Estatal Amazónica, Puyo, Ecuador. mayraheras71@gmail.com

\section{ARTÍCULO DE INVESTIGACIÓN}

Recibido: 22 de marzo de 2021

Aceptado: 24 de septiembre de 2021

\section{RESUMEN}

Esta contribución de estrategias, es el análisis del posicionamiento como aporte para la inserción laboral de los graduados de la carrera de turismo de la Universidad Estatal Amazónica de la ciudad del Puyo, provincia de Pastaza, Ecuador, el objetivo principal es el de diseñar estrategias de posicionamiento, mediante el diagnóstico de la situación actual de los graduados y conociendo los factores que influencian la inserción laboral. El estudio se encuentra enmarcado en la línea de investigación de gestión turística sostenible, aplicando una metodología de investigación-acción, con un paradigma socio-crítico, realizando un análisis descriptivo de tipo cualitativo y cuantitativo. Se realizó una síntesis de los fundamentos teóricos en fuentes primarias y secundarias, a más de la aplicación de encuestas como instrumento de recolección de datos. Es importante mencionar que el estudio reflejó que el $30 \%$ de los 80 graduados aún no tienen trabajo. Adicionalmente, el $75 \%$ desempeña un cargo que no tiene relación con su formación profesional; han mencionado que se requiere fortalecer los aspectos de la experiencia laboral, una actualización de mallas curriculares y brindar cursos de emprendimiento. Se elaboraron ocho estrategias con sus 
respectivas acciones y propósitos, basándose principalmente en alianzas estratégicas con actores público, privado y comunitario de la provincia de Pastaza.

Palabras claves: estrategias de posicionamiento, talento humano, inserción laboral, turismo.

\section{ABSTRACT}

This research is focused in the analysis of positioning strategies bound for labor insertion of tourism graduates of Universidad Estatal Amazónica, in the Puyo city, Pastaza province, Ecuador. The aim is to design positioning strategies through situational diagnostic of graduates and the analysis of factors influencing their labor insertion. This study is embedded in the research line of sustainable touristic management, applying a sociocritical paradigm with a qualitative and quantitative descriptive analysis. A synthesis of theoretic fundamentals of primary and secondary level sources was carried out as well as the use of surveys for data collection. It is important to mention that $30 \%$ out of 80 graduates have not found a job yet. In addition, $75 \%$ are working on a job not involved in their profession. Graduates have also expressed that it is quite important to improve their working experience and the need for a Curriculum updating and training in entrepreneurship. Eight strategies were developed in this study, involving partnership with public, private and community actors of Pastaza province.

Keywords: positioning strategies human talent, labor insertion, tourism.

\section{INTRODUCCIÓN}

El sector del turismo es una actividad de gran importancia y que a la vez demanda de una legislación, formación y capacitación de talento humano, se requiere que esta formación a través de la educación superior sea capaz de formar profesionales competentes que satisfagan las necesidades de la sociedad.

Es por ello que, los graduados de la facultad de turismo de la Universidad Estatal Amazónica deben poseer una formación integral que les permita hacer frente a las nuevas tendencias del mercado, que les permita insertarse laboralmente, tanto en empresas públicas como privadas, de esta manera disminuir el porcentaje de graduados que se encuentran desempleados y promover su estabilidad personal, social y laboral.

Es importante analizar cada aspecto del posicionamiento laboral, así como las diferentes estrategias para la inserción que serán abordadas, las mismas que han sido desarrolladas de tal manera que se puedan ejecutar de forma óptima y disminuir el desempleo.

La investigación se encuentra apoyada por métodos y técnicas para el diseño de estas estrategias; como la técnica del focus group, la herramienta FODA y cada una de las matrices de sistematización de los empresarios; cabe destacar que se desarrolló un análisis descriptivo 
con la utilización de encuestas para diagnosticar principalmente a los graduados de la carrera de turismo y de esta manera, al conocer los factores, lo que requiere, se elaboraron las estrategias de una manera eficaz.

\section{REVISIÓN TEÓRICA}

\section{Enfoque del trabajo desde la inserción laboral}

El trabajo tiene varios enfoques dentro de los cuales los asuntos más relativos es el empleo y los efectos sobre el bienestar social de los individuos son ejes centrales de los análisis económicos. Sin embargo, la mayoría son conclusiones distintas y contrarias pues las modalidades afectan a las políticas económicas de quienes las implementan (López y Montero 2005).

La relación entre el trabajador y el empleador bajo ciertas condiciones a cambio de remuneración, en la que se crea derechos y obligaciones recíprocas entre las dos partes. Depende tanto de la realidad de cada localidad, país y su cultura, pero la universalización de derechos y obligaciones influye en el ámbito laboral que debe ser aplicado a las normas vigentes (OIT, 2004).

\section{La inserción laboral}

Según Vidal y Ortega (2003) afirman que: El conocimiento sobre la realidad de la inserción laboral es un medio crucial para la protección de los jóvenes y por ello debe articularse expresamente una línea estratégica de optimización de los sistemas de información tanto en el ámbito local y autonómico de la Administración y entidades civiles como en el ámbito general (p. 23).

\section{La situación de los jóvenes universitarios}

Los jóvenes universitarios desde el enfoque laboral han tenido varias dificultades a lo largo del tiempo tal como se encuentra en los escritos de la inserción laboral de los egresados universitarios que data desde hace 50 años atrás, como lo manifiestan Pérez, Díaz, y Rodríguez, (2002), quienes señalan que en la década de los setenta el movimiento estudiantil y la inteligencia contestataria cuestionan a la universidad, por lo que considera la baja calidad de la actividad científica y su vida intelectual y comienza a preocuparse por la eficacia de la universidad a la hora de prepararle para las profesiones del porvenir.

Hay un notorio crecimiento en las universidades de una oferta de profesionales con formación en ciertas ramas como la de turismo lo que aumenta la oferta y disminuye la demanda, pues la competencia es mayor. 


\section{Empleo en el sector turístico}

Para el Ministerio de Turismo (2002), en correspondencia con el artículo 5 de la Ley de Turismo (2002), considera como actividades turísticas las siguientes:

a) Alojamiento

b) Servicio de alimentos y bebidas

c) Transportación, cuando se dedica principalmente al turismo; inclusive el transporte aéreo, marítimo, fluvial, terrestre y el alquiler de vehículos para este propósito

d) Operación, cuando las agencias de viajes provean su propio transporte, esa actividad se considerará parte del agenciamiento

e) La de intermediación, agencia de servicios turísticos y organizadoras de eventos, congresos y convenciones

f) Casinos, salas de juego (bingo - mecánicos), hipódromos y parques de atracciones estables.

La actividad turística en sí, abarca una amplia gama de actividades y tipos de establecimientos, cada uno especializado en su tipología y categoría, según los estándares de calidad exigidos por los entes reguladores. Para Fisher y Amabile (2009), "el valor añadido del producto o servicio es un reflejo de ideas, diseño, marketing creativos e innovadores y ellos son fruto de mano de obra preparada" (p.47). Consideran relevante mejorar el proceso de transferencia de información a diferentes niveles de la empresa. En este sentido, el profesional en turismo no necesariamente garantiza el acceso al mercado laboral, ya que en el proceso de inserción no se evalúa exclusivamente el nivel de educación, sino también valora la previa experiencia práctica.

\section{Consideraciones generales del Turismo}

Para Martín de la Rosa (2003), el turismo se caracteriza por su dinamismo, se producen una serie de consecuencias que desencadenan su desarrollo. Institucionalización de las vacaciones pagadas, adelantos en los medios de transportes, cierta estabilidad económica que permite ingresos adicionales para gastar en las vacaciones, instauración del consumo masivo, y por supuesto, la firme convicción de que unas vacaciones son necesarias y merecida recompensa a la rutinaria y dura vida laboral (p.75).

Jafari (2005), en relación a la importancia del Turismo se refiere a que hoy en día el turismo es celebrado como una decisiva fuerza económica global y una gigantesca industria mundial. Muchas publicaciones de la Organización Mundial del Turismo (OMT), entre otras, dan buena cuenta de su estable crecimiento desde la Segunda Guerra Mundial. La importancia del turismo es innegable, como lo describe Toselli (2006), que expresa que puede ser un positivo 
instrumento de desarrollo local y regional, entendido esto último desde una visión socioeconómica que permita una equitativa distribución de los beneficios, ya sean de carácter económico, social y cultural en las comunidades anfitrionas.

En las publicaciones realizadas por Guevara (2006), argumenta que el turismo se ha constituido en una actividad económica y una práctica social que ha transitado por distintos momentos, esta merece un cuidadoso seguimiento a través de la generación de estudios surgidos desde diferentes disciplinas sociales que contribuyan a la construcción del conocimiento de lo turístico.

Molina (2000) considera que a lo largo del siglo veinte el turismo ha experimentado profundas transformaciones, derivadas de los grandes cambios sociales y políticos manifestados en una gran diversidad de países y continentes. La necesidad creciente de adaptación a los nuevos paradigmas del escenario turístico mundial hace imprescindible considerar el capital humano como uno de los factores clave para el desarrollo de estrategias competitivas, (Bañuls, Rodríguez, y Jiménez, 2007).

\section{Enseñanza superior en el turismo: la universidad y la empleabilidad}

La Universidad hace su rol de formación académica por su conocimiento teórico, sin embargo, la falta de habilidades prácticas suele representar un escollo en su proceso de inserción laboral al referirnos a los graduados, repercutiendo directamente en su vida laboral como profesional al desempeñar su trabajo (Santiago, 2008).

Según Metcalfe (2013), entiende por empleabilidad a una combinación entre el conocimiento adquirido en la universidad y el desarrollo de competencias adquiridas en la universidad y desarrollo de competencias requeridas por las empresas. Esto responde a la necesidad de actualizar el papel de la universidad en el dinámico contexto de la economía del conocimiento, en el que se espera cada vez más que se actué como proveedor del conocimiento científico y tecnológico y de las tecnologías aplicadas para la empresa (Plaza, Andrade, y Marcillo, 2016).

Medina (2012) también hace referencia un aporte en este sentido y menciona que en los actuales momentos en las universidades del Ecuador se habla de un proceso de capacitación y formación de docentes investigadores para de esta manera enriquecer el acervo cultural de nuestros estudiantes y que la labor investigativa ha demostrado su utilidad teniendo como resultado obras de gran magnitud; lo que ha convertido a las universidades en un importante ente estatal y/o privado de desarrollo, aportando de forma directa al fortalecimiento en todos sus ámbitos, de las sociedades que las rodean. 


\section{La Universidad como formador de profesionales}

Ninguna sociedad se puede desarrollar sin educación, de allí su importancia; Según Armengol y Casas (2005), menciona que la universidad es un factor fundamental para la transformación y el progreso de las sociedades actuales, sean desarrolladas 0 subdesarrolladas.

Bozu y Canto (2009) estipulan que: Las universidades son las encargadas de formar personas que puedan ser capaces de seleccionar, actualizar y utilizar el conocimiento en un contexto específico, que sean capaces de aprender en diferentes contextos y modalidades y a lo largo de toda la vida y que puedan entender el potencial de lo que van aprendiendo para que puedan adaptar el conocimiento a situaciones nuevas (p. 22).

La formación académica debe propender a la certificación profesional de conocimientos, habilidades, actitudes, valores y competencias, que respondan a las necesidades del entorno económico, social y cultural (Cuevas, 2011).

\section{Importancia de la formación profesional}

La mejor forma de estar acorde y preparado a los cambios vertiginosos que presenta el sector del turismo es estar capacitado y en constante actualización. "Educar de manera adecuada a quienes forman parte del sistema turístico, generando en ellos una visión amplia del sector, que los capacite para gestionar de manera adecuada" (Damm, 1998).

\section{Carrera de Turismo}

La formación debe ser integral basada en el emprendimiento y el desarrollo sustentable dentro de la filosofía de las artes liberales, la concienciación a un uso correcto de los recursos naturales, aprovechando la cultura e historia e incluyente con las comunidades locales. La carrera formativa también se asocia a procesos permanentes y propicia el desarrollo profesional, social y personal (Cuevas, Herrera, y Vargas, 2011).

\section{Estrategias de posicionamiento}

Hernández y Palafox (2012), establecen que las estrategias corresponden a la forma de reaccionar oportunamente ante las circunstancias cambiantes del ambiente, a través de tácticas y operaciones.

Las empresas para ser competitivas establecen como estrategia la competencia en sus empleados, en el ámbito laboral como una fortaleza indiscutible y que a la vez les diferencia de la competencia del mercado dándoles mucha ventaja competitiva (SECTUR, 2005).

Ries y Trout (2000) en el tema de que el posicionamiento comienza: El posicionamiento no se refiere al producto, sino a lo que se hace con la mente de los probables clientes 0 
personas a las que se quiere influir; o sea, cómo se ubica el producto en la mente de éstos, y como generar la necesidad y la atracción de éstos, al utilizar las técnicas apropiadas o simplemente innovaciones recientes en el mercado; pues así nace la creatividad profesional.

\section{Importancia de las estrategias}

Una adecuada estrategia de posicionamiento permitirá una mejor inserción de los profesionales en el ámbito laboral, ya dependerá de las acciones que se sigan para tener el éxito esperado, permitiendo desde el puesto de trabajo solucionar los problemas que se presenten, para Juri (2015) establece que: "La búsqueda de la formación profesional competente con conocimientos básicos e indispensables para el desarrollo de una profesión, pero sobre todo, con una lógica que permita al futuro profesional una confrontación creativa ante las situaciones cambiantes y problemáticas que son el signo de nuestros días, nos ayudan a diferenciarnos de los demás competidores".

\section{MATERIALES Y MÉTODOS}

El estudio fue de tipo descriptivo, in situ, que permitió resolver problemas prácticos, por su naturaleza es una investigación de tipo mixto: cualitativa y cuantitativa, ya que se realizaron entrevistas y encuetas, tanto a personas profesionales en turismo inmersos en el ámbito profesional y a los graduados de la Carrera de Turismo de la Universidad Estatal Amazónica respectivamente. La línea de investigación es la 5 de la Universidad Estatal Amazónica: Turismo y Patrimonios; literal a): Gestión turística sostenible.

Se empleó como estrategia metodológica la de investigación- acción, inscrita en el paradigma socio-crítico, por ser tratado a partir de una situación actual o realidad del entorno, lo que permitió identificar los factores de incidencia respecto al objeto de estudio, esto es a partir de datos reales de los graduados en las promociones entre el 2009 y el 2016 de la Carrera de Turismo de la UEA y su inserción en el mercado laboral. Los métodos empleados fueron teóricos, analizando información en fuentes primarias y secundarias, todas relacionadas a la actividad turística; se desarrolló un análisis inductivo-deductivo, a más de sistémico-estructura; el siguiente método es el empírico utilizando la técnica de la encuesta, con un cuestionario semiestructurado.

Se ejecutó en dos fases, con una muestra piloto y posteriormente al total del tamaño muestral, es importante recalcar que se usó el proceso estadístico de D’Alessio (2014), que consta de siete fases, en las que se destaca la matriz FODA y la técnica del Focus Group. El análisis fue cualitativo/cuantitativo con el método porcentual, con la utilización de Programa Microsoft Excel 2010 y Software Statiscal Package for the Social Science (SPSS). 
En base a lo anterior, el estudio presenta el resultado de acerca del posicionamiento laboral, a través de las historias de 80 graduados de la Carrera de Turismo, quienes comparten características en común y a quienes se aplicó la encuesta para determinar cómo es su situación actual en el ámbito laboral, y de qué manera se puede cambiar tales situaciones de desempleo.

\section{Análisis de Datos}

La provincia de Pastaza se caracteriza por tener zonas naturales y culturales que son explotados turísticamente, consta de una infraestructura de servicios turísticos en los que se resalta las 5 actividades principales como son: alimentos y bebidas, alojamiento, operación e intermediación, parques y atracciones estables y transporte turístico.

\section{Tabla 1}

Establecimientos Registrados en el Catastro Turístico del Ministerio de Turismo.

\begin{tabular}{|c|c|}
\hline \multicolumn{2}{|c|}{ PRESTADORES DE SERVICIOS TURÍSTICOS } \\
\hline \multicolumn{2}{|l|}{ ALIMENTOS Y BEBIDAS } \\
\hline Bar & 36 \\
\hline Cafetería & 9 \\
\hline Fuente de Soda & 31 \\
\hline Restaurante & 101 \\
\hline TOTAL & 11 \\
\hline \multicolumn{2}{|l|}{ ALOJAMIENTO } \\
\hline Casa de huéspedes & 3 \\
\hline Hostal & 33 \\
\hline Hostería & 12 \\
\hline Hotel & 13 \\
\hline TOTAL & 61 \\
\hline \multicolumn{2}{|c|}{ OPERACIÓN E INTERMEDIACIÓN } \\
\hline Operadores Turísticos & 6 \\
\hline Agencias de Viaje Dual & 2 \\
\hline Agencias de Viaje Internacional & 2 \\
\hline TOTAL & 10 \\
\hline \multicolumn{2}{|c|}{ PARQUES DE ATRACCIONES ESTABLES } \\
\hline Centro de Recepciones Turísticas & 3 \\
\hline Discoteca & 10 \\
\hline Sala de Recepciones y Banquetes & 2 \\
\hline Termas y Balnearios & 5 \\
\hline TOTAL & 20 \\
\hline \multicolumn{2}{|l|}{ TRANSPORTE TURÍSTICO } \\
\hline Transporte terrestre & 2 \\
\hline TOTAL & 2 \\
\hline TOTAL & 21 \\
\hline
\end{tabular}

Fuente: Ministerio de Turismo de Pastaza (2018).

Desde el año 2009 hasta el año 2016, la Universidad Estatal Amazónica ha brindado a la sociedad un total de 126 profesionales en turismo, con títulos de tercer nivel. Los mismos que serán los encargados de resolver los problemas existentes en este campo, permitiendo el 
desarrollo de la actividad turística, cubriendo las fuentes las de empleo y necesidades laborales tanto en el sector privado y público.

\section{Tabla 2}

Graduados en la Carrera de Turismo en la UEA, período 2009-2016.

\begin{tabular}{cc}
\hline \multicolumn{2}{c}{ GRADUADOS DE LA CARRERA DE } \\
TURISMO \\
\hline Año & Número de graduados \\
2009 & 12 \\
2010 & 0 \\
2011 & 1 \\
2012 & 13 \\
2013 & 22 \\
2014 & 14 \\
2015 & 19 \\
2016 & 45 \\
TOTAL & 126 \\
\hline
\end{tabular}

Fuente: Universidad Estatal Amazónica/Secretaría Académica (2018).

Conforme el diseño metodológico de la presente investigación y con el propósito de conocer la inserción laboral de los graduados de la Carrera en Turismo de la UEA se aplicó la encuesta a 80 graduados del periodo $2009-2016$.

\section{Tabla 3}

Estudios con cursos de actualización relacionados a su perfil profesional después de graduarse en la UEA.

\begin{tabular}{cccccc}
\hline VARIABLE & FRECUENCIA & PORCENTAJE & $\begin{array}{c}\text { PORCENTAJE } \\
\text { VÁLIDO }\end{array}$ & $\begin{array}{c}\text { PORCENTAJE } \\
\text { ACUMULADO }\end{array}$ \\
\hline \multirow{3}{*}{ Válido } & $\mathrm{Si}$ & 8 & $10 \%$ & $10 \%$ & $10 \%$ \\
& No & 72 & $90 \%$ & $90 \%$ & $100 \%$ \\
& Total & 80 & $100 \%$ & $100 \%$ & \\
\hline
\end{tabular}

Fuente: Elaboración propia.

\section{Tabla 4}

Nivel de estudios actuales.

\begin{tabular}{|c|c|c|c|c|c|}
\hline \multicolumn{2}{|c|}{ VARIABLE } & \multirow{2}{*}{$\begin{array}{c}\text { FRECUENCIA } \\
69\end{array}$} & \multirow{2}{*}{$\begin{array}{c}\text { PORCENTAJE } \\
86,25 \%\end{array}$} & \multirow{2}{*}{$\begin{array}{c}\text { PORCENTAJE } \\
\text { VÁLIDO } \\
86,25 \%\end{array}$} & \multirow{2}{*}{$\begin{array}{c}\text { PORCENTAJE } \\
\text { ACUMULADO } \\
86,25 \%\end{array}$} \\
\hline \multirow{5}{*}{ Válido } & Ninguno & & & & \\
\hline & Especialidad & 2 & $2,50 \%$ & $2,50 \%$ & $88,80 \%$ \\
\hline & Maestría & 9 & $11,25 \%$ & $11,25 \%$ & $100 \%$ \\
\hline & Doctorado & 0 & $0,00 \%$ & $0,00 \%$ & \\
\hline & Total & 80 & $100 \%$ & $100 \%$ & \\
\hline
\end{tabular}

Fuente: Elaboración propia. 
El $90 \%$ de los encuestados menciona que no ha realizado cursos según su perfil profesional, tan solo el $10 \%$ si ha continuado con cursos relacionados a la carrera profesional, es necesario se pueda generar oportunidades de capacitación para los estudiantes que propicien la mejora de su profesión.

Para el $86,25 \%$ de los encuestados no han logrado un estudio de cuarto nivel, sin embargo, el 11,25\% menciona que ha obtenido una maestría y otros las están cursando, tan solo el $2,50 \%$ ha realizado una especialidad.

\section{Tabla 5}

Tiempo que se tardó en obtener un trabajo

\begin{tabular}{lccccc}
\hline VARIABLE & FRECUENCIA & PORCENTAJE & $\begin{array}{c}\text { PORCENTAJE } \\
\text { VÁLIDO }\end{array}$ & $\begin{array}{c}\text { PORCENTAJE } \\
\text { ACUMULADO }\end{array}$ \\
\hline Menos de un & 17 & $21,30 \%$ & $21,30 \%$ & $21,30 \%$ \\
año & 23 & $28,80 \%$ & $28,80 \%$ & $50,00 \%$ \\
Un año & 10 & $12,50 \%$ & $12,50 \%$ & $62,50 \%$ \\
Dos años & 2 & $2,50 \%$ & $2,50 \%$ & $65,00 \%$ \\
Válido & Tres años & $5,00 \%$ & $5,00 \%$ & $70,00 \%$ \\
Cuatro años & 4 & $30,00 \%$ & $30,00 \%$ & $100 \%$ \\
Aún no tiene & 24 & $100 \%$ & $100 \%$ & \\
trabajo & 80 & & & \\
Total & & &
\end{tabular}

Fuente: Elaboración propia.

La mayor parte de los encuestados en un 30\% aún no tiene trabajo; para el 28,75 se tardó más de un año, sin embargo, para un $21,25 \%$ se tardó menos de un año, para el $12,50 \%$ se tardó dos años en conseguir un trabajo, el 5\% se tardó cuatro años y una mínima de 2,50\% tardo tres años.

\section{Tabla 6}

El cargo que ocupa está relacionado con su formación profesional

\begin{tabular}{cccccc}
\hline \multicolumn{2}{c}{ VARIABLE } & FRECUENCIA & PORCENTAJE & $\begin{array}{c}\text { PORCENTAJE } \\
\text { VÁLIDO }\end{array}$ & $\begin{array}{c}\text { PORCENTAJE } \\
\text { ACUMULADO }\end{array}$ \\
\hline \multirow{3}{*}{ Válido } & $\mathrm{Si}$ & 20 & $25,00 \%$ & $25,00 \%$ & $25,00 \%$ \\
& No & 60 & $75,00 \%$ & $75,00 \%$ & $100 \%$ \\
& Total & 80 & $100 \%$ & $100 \%$ & \\
\hline
\end{tabular}

Fuente: Elaboración propia.

Para el 75\% de los encuestados dice que su cargo que desempeña no está en relación con la formación profesional y tan solo el $25 \%$ si está en relación con la formación profesional. 


\section{Tabla 7}

¿Cuánto tiempo se encontraba desempleado en años y meses?

\begin{tabular}{|c|c|c|c|c|c|}
\hline \multicolumn{2}{|c|}{ VARIABLE } & FRECUENCIA & PORCENTAJE & $\begin{array}{c}\text { PORCENTAJE } \\
\text { VÁLIDO }\end{array}$ & $\begin{array}{l}\text { PORCENTAJE } \\
\text { ACUMULADO }\end{array}$ \\
\hline \multirow{7}{*}{ Válido } & $n / a$ & 55 & $68,80 \%$ & $68,80 \%$ & $68,80 \%$ \\
\hline & 1 año & 7 & $8,80 \%$ & $8,80 \%$ & $77,50 \%$ \\
\hline & 2 años & 9 & $11,30 \%$ & $11,30 \%$ & $88,80 \%$ \\
\hline & 3 años & 3 & $3,80 \%$ & $3,80 \%$ & $92,50 \%$ \\
\hline & 1 a 5 meses & 3 & $3,80 \%$ & $3,80 \%$ & $96,30 \%$ \\
\hline & $\begin{array}{l}6 \quad \mathrm{a} \\
\text { meses }\end{array}$ & 3 & $3,80 \%$ & $3,80 \%$ & $100 \%$ \\
\hline & Total & 80 & $100 \%$ & $100 \%$ & \\
\hline
\end{tabular}

Fuente: Elaboración propia.

De los encuestados el $11,25 \%$ el tiempo que se encontraba desempleado fue de 2 años, y el 8,75\% un año, y en porcentajes similares del 3,75\% 3 años, 1 a 5 meses y de 6 a 11 meses y para el $68,75 \%$ no aplica.

\section{Tabla 8}

¿Cuáles son los principales factores que inciden para no encontrar trabajo?

\begin{tabular}{|c|c|c|c|c|c|}
\hline & VARIABLE & FRECUENCIA & PORCENTAJE & $\begin{array}{l}\text { PORCENTAJE } \\
\text { VÁLIDO }\end{array}$ & $\begin{array}{l}\text { PORCENTAJE } \\
\text { ACUMULADO }\end{array}$ \\
\hline & $\begin{array}{ll}\text { Deficiente } & \text { formación } \\
\text { académica } & \end{array}$ & 5 & $6,3 \%$ & $6,3 \%$ & $6,3 \%$ \\
\hline & $\begin{array}{l}\text { Pocas horas de } \\
\text { prácticas } \\
\text { preprofesionales }\end{array}$ & 16 & $20,00 \%$ & $20,00 \%$ & $26,3 \%$ \\
\hline & Competencia desleal & 14 & $17,5 \%$ & $17,5 \%$ & $43,8 \%$ \\
\hline & $\begin{array}{l}\text { Reducidas plazas de } \\
\text { trabajo }\end{array}$ & 15 & $18,8 \%$ & $18,8 \%$ & $62,5 \%$ \\
\hline valıdo & $\begin{array}{l}\text { Falta de experiencia } \\
\text { profesional }\end{array}$ & 13 & $16,3 \%$ & $16,3 \%$ & $78,8 \%$ \\
\hline & $\begin{array}{l}\text { Falta de destrezas y } \\
\text { habilidades propias de } \\
\text { su profesión }\end{array}$ & 10 & $12,5 \%$ & $12,5 \%$ & $91,3 \%$ \\
\hline & $\begin{array}{l}\text { Miedo e inseguridad } \\
\text { personal }\end{array}$ & 7 & $8,8 \%$ & $8,8 \%$ & $100,0 \%$ \\
\hline & Total & 80 & $100 \%$ & $100 \%$ & \\
\hline
\end{tabular}

Fuente: Elaboración propia.

El 20\% manifiestan que uno de los factores que inciden para no encontrar trabajo es porque hay pocas horas de práctica pre-profesionales, el 18,75\% dice que, por las reducidas plazas de trabajo, el $17,50 \%$ por la competencia desleal, el 16,25\% menciona por la falta de experiencia, el $12,50 \%$ dice por la falta de destrezas y facilidades propicias de su profesión, y el 8,75 al miedo e inseguridad personal, y 6,25\% el deficiente formación académica. 


\section{Tabla 9}

¿El diseño de las estrategias de posicionamiento, aportaran en la inserción laboral de los graduados de la carrera de turismo de la UEA?

\begin{tabular}{cccccc}
\hline \multicolumn{2}{c}{ VARIABLE } & FRECUENCIA & PORCENTAJE & $\begin{array}{c}\text { PORCENTAJE } \\
\text { VÁLIDO }\end{array}$ & $\begin{array}{c}\text { PORCENTAJE } \\
\text { ACUMULADO }\end{array}$ \\
\hline \multirow{3}{*}{ Válido } & $\mathrm{Si}$ & 76 & $95,0 \%$ & $95,0 \%$ & $95,0 \%$ \\
& No & 4 & $5,0 \%$ & $5,0 \%$ & $100,0 \%$ \\
& Total & 80 & $100,0 \%$ & $100,0 \%$ & \\
\hline
\end{tabular}

Fuente: Elaboración propia.

Los encuestados en un 95\% consideran que la UEA debe desarrollar estrategias de posicionamiento para que los graduados tengan mejor inserción laboral y tan solo el $5 \%$ dijo que no lo consideran.

\section{Tabla 10}

¿Cuáles considera Usted, que sería los campos en los que UEA deberían fortalecerse y 10 implementar?

\begin{tabular}{|c|c|c|c|c|c|}
\hline & VARIABLE & FRECUENCIA & PORCENTAJE & $\begin{array}{l}\text { PORCENTAJE } \\
\text { VÁLIDO }\end{array}$ & $\begin{array}{l}\text { PORCENTAJE } \\
\text { ACUMULADO }\end{array}$ \\
\hline \multirow{12}{*}{ Válido } & $\begin{array}{l}\text { Actualizar mallas } \\
\text { curriculares }\end{array}$ & 7 & $8,80 \%$ & $8,80 \%$ & $8,80 \%$ \\
\hline & $\begin{array}{l}\text { Aumentar horas de } \\
\text { prácticas } \\
\text { preprofesionales }\end{array}$ & 13 & $16,3 \%$ & $16,3 \%$ & $25,00 \%$ \\
\hline & $\begin{array}{l}\text { Mejorar la calidad de } \\
\text { formación académica }\end{array}$ & 5 & $6,3 \%$ & $6,3 \%$ & $31,3 \%$ \\
\hline & $\begin{array}{l}\text { Establecer alianzas } \\
\text { estratégicas en red } \\
\text { Establecer escenarios }\end{array}$ & 12 & $15,0 \%$ & $15,0 \%$ & $46,3 \%$ \\
\hline & de participación activa & 16 & $20,0 \%$ & $20,0 \%$ & $66,3 \%$ \\
\hline & $\begin{array}{l}\text { para obtener } \\
\text { experiencia laboral }\end{array}$ & & & & \\
\hline & $\begin{array}{l}\text { Seguimiento } \\
\text { graduados }\end{array}$ & 8 & $10,0 \%$ & $10,0 \%$ & $76,3 \%$ \\
\hline & $\begin{array}{l}\text { Cursos } \\
\text { emprendimientos de } \\
\text { motivación personal }\end{array}$ & 5 & $6,3 \%$ & $6,3 \%$ & $82,5 \%$ \\
\hline & Cursos sobre técnicas & & & & \\
\hline & $\begin{array}{l}\text { de búsqueda de } \\
\text { empleo }\end{array}$ & 9 & $11,3 \%$ & $11,3 \%$ & $93,8 \%$ \\
\hline & Otros & 5 & $6,3 \%$ & $6,3 \%$ & $100,0 \%$ \\
\hline & Total & 80 & $100,0 \%$ & $100,0 \%$ & \\
\hline
\end{tabular}

Fuente: Elaboración propia.

El $20 \%$ consideran que los campos en los que la UEA deben fortalecerse en escenarios de participación activa para obtener experiencia laboral, el 16, 25\% debe aumentar horas de prácticas pre-profesionales, el 15\% deben establecer alianzas estratégicas en la red, el $11,30 \%$ en cursos sobre técnicas de empleo, el $10 \%$ mejorar el seguimiento a graduados, el $8,75 \%$ deben actualizar las mallas curriculares y deben mejorar la formación académica, y los cursos de emprendimiento personal. 


\section{RESULTADOS}

\section{Comprobación de la Hipótesis}

Para la comprobación de hipótesis se hizo una pregunta donde se evaluaba la percepción de los encuestados relacionada a si el desarrollo de estrategias de posicionamiento puede aportar a una mejor inserción laboral de los graduados.

\section{Tabla 11}

Pregunta para comprobación de hipótesis

\begin{tabular}{lcc}
\hline \multicolumn{1}{c}{ HIPÓTESIS } & Sí & NO \\
\hline ¿El diseño de las estrategias de posicionamiento, aportarán en la inserción laboral de los & & \\
graduados de la carrera de turismo de la UEA? & \\
\hline
\end{tabular}

Fuente: Elaboración propia.

La comprobación de hipótesis se hizo a través de una prueba de homogeneidad chi cuadrado con el objetivo de verificar si existe diferencia dentro de cada categoría (SI/NO).

Para calcular las frecuencias esperadas se utilizó la fórmula planteada por (Lind D, Marchal W. y Wathen S., 2011)

Frecuencia Esperada $=\quad$ Suma de frecuencias de todas las categorías Número de categorías

El cálculo del estadístico de prueba chi cuadrado se realizó con la siguiente fórmula:

$$
x^{2}=\Sigma\left[\frac{(f o-f e) 2}{f e}\right]
$$

Al reemplazar los valores en la fórmula planteada se obtiene un estadístico de prueba chi cuadrado igual a: 64.8; por otro lado, los grados de libertad dan un valor igual a 1. Este valor obtenido debe compararse con el valor crítico de la prueba chi cuadrado con 1 grado de libertad y a un nivel de significancia de 0.05 el cual es igual a: 3.84. Si el estadístico de prueba chi cuadrado es mayor que el valor crítico, se rechaza la hipótesis nula de homogeneidad entre las categorías de cada pregunta. En este caso vemos que $64.8>3.84$ por lo que concluimos que las categorías de respuesta tienen una diferencia estadísticamente significativa.

Con estos resultados se puede afirmar que, dado que la mayoría de encuestados manifiesta su acuerdo con la pregunta realizada, se comprueba la hipótesis de investigación, es decir, que el diseño de estrategias de posicionamiento aporta positivamente en la inserción laboral de los graduados de la carrera de Turismo de la UEA. 


\section{Resultados del Focus Group}

Los grupos focales se realizaron con 15 personas con un rango de edad de 25 a 65 años. Se basa en las dos preguntas relevantes:

- ¿Conoce que la mayor parte de los graduados de la carrera de turismo de la UEA, no logran insertarse laboralmente en Pastaza?

- ¿Qué solución puede darse para que los graduados puedan insertarse laboralmente en las empresas turísticas locales?

La mayor parte de los asistentes concuerdan que la oferta de los graduados de la carrera de turismo de la UEA es muy alta en relación a la capacidad de la demanda instalada y capacidades de las empresas turísticas, pues la actividad turística en los últimos cinco años se ha venido a menos.

Con respecto a que soluciones se puedan dar, en su mayoría mencionaban que, si la realidad de la economía basada en turismo fuera diferente se podría generar más oportunidades de empleo, pero el turismo cada vez cuenta con menor presencia, por lo que las plazas de empleo son reducidas.

\section{Propuesta}

La propuesta generó estrategias de posicionamiento para que los graduados de la Universidad Estatal Amazónica tengan una mejor inserción laboral pudiendo generar nuevas expectativas y oportunidades para los graduados, las estrategias permiten el incremento de oportunidades de inserción laboral, se convierte en las opciones más apropiadas para desarrollar esta industria y en concordancia al resto de la dinámica generada por esta actividad desde el punto de vista de la academia y de la empresa pública, privada y comunitaria, quienes son los que buscan de los profesionales para apoyar la gestión laboral.

\section{Misión}

Propiciar el fortalecimiento de inserción laboral de los graduados de la Carrera de Turismo de la Universidad Estatal Amazónica mediante la implementación de estrategias académicas y de experticia en la actividad turística.

\section{Visión}

Reconocer a la actividad turística como el medio diversificador de las economías locales mediante el incremento de la productividad de la industria turística, la diversificación de la oferta laboral y de inversiones, que permitan generar empleo y con ello alcanzar un mayor nivel de bienestar económico de los graduados de la Carrera de Turismo de la Universidad Estatal Amazónica. 


\section{Objetivos}

\section{Objetivo General:}

- Diseñar estrategias de posicionamiento que permitan la inserción laboral de los graduados de la Carrera de Turismo de la Universidad Estatal Amazónica.

\section{Objetivos Específicos:}

- Identificar los actores que intervienen en el plan estratégico.

- Proponer estrategias acordes a la realidad local.

- Establecer un plan operativo y cronograma para la implementación de las estrategias de posicionamiento.

\section{Estrategias de posicionamiento}

Se elaboró una matriz FODA y de impacto cruzado que permitió identificar las estrategias de posicionamiento para la inserción laboral de los graduados en la Carrera de Turismo de la Universidad Estatal Amazónica, para desarrollar la propuesta en base a la realidad actual.

Tabla 12.

Listado de factores claves

\begin{tabular}{|c|c|c|}
\hline $\begin{array}{l}\text { FACTORES } \\
\text { INTERNOS }\end{array}$ & FORTALEZAS & DEBILIDADES \\
\hline Gobernanza & $\begin{array}{l}\text { - Buena relación de gobernabilidad de } \\
\text { la academia con las autoridades } \\
\text { locales. } \\
\text { - Ciudadanos organizados. } \\
\text { - Excelente trabajo entre empresa } \\
\text { pública y privada. }\end{array}$ & $\begin{array}{l}\text { - Las autoridades no apoyan a los proyectos } \\
\text { turísticos emblemáticos. } \\
\text { - No hay iniciativas locales de las autoridades } \\
\text { para definir al turismo como prioridad. }\end{array}$ \\
\hline $\begin{array}{l}\text { Productos y } \\
\text { servicios }\end{array}$ & $\begin{array}{l}\text { - } \quad \text { Formación académica adecuada. } \\
\text { - Oferta profesional en turismo. }\end{array}$ & - Inexistencia de un trabajo seguro. \\
\hline Mercadeo & $\begin{array}{l}\text { - } \quad \text { Forma profesional en turismo. } \\
\text { - Participación con la comunidad. }\end{array}$ & - Falta de un centro de oferta de trabajo. \\
\hline & $\begin{array}{l}\text { - } \quad \text { Conocimientos ampliados en turismo. } \\
\text { - } \quad \text { Participación con la comunidad. }\end{array}$ & $\begin{array}{l}\text { - La comunidad no cuenta con alcantarillado. } \\
\text { - No existe un plan de desarrollo turístico } \\
\text { provincial. }\end{array}$ \\
\hline $\begin{array}{l}\text { desarrollo } \\
\text { destigacion y }\end{array}$ & & $\begin{array}{l}\text { - Falta de especialización técnica en } \\
\text { gastronomía, operación en deporte de } \\
\text { aventura. }\end{array}$ \\
\hline Finanzas & & - $\quad$ Baja en liquidez por falta de efectivo. \\
\hline $\begin{array}{l}\text { FACTORES } \\
\text { EXTERNOS }\end{array}$ & OPORTUNIDAD & AMENAZA \\
\hline Social & $\begin{array}{l}\text { - Contar con un centro educativo de } \\
\text { primera, equipamiento y laboratorios. } \\
\text { - Contar con un centro de } \\
\text { investigación. }\end{array}$ & $\begin{array}{l}\text { - Pérdida de la cultura a través de la migración. } \\
\text { - Inseguridad. }\end{array}$ \\
\hline Económico & $\begin{array}{l}\text { - Se financian empresas turísticas con } \\
\text { préstamos CFN y BanEcuador. } \\
\text { - Programa para la difusión y } \\
\text { publicidad de los atractivos. }\end{array}$ & $\begin{array}{l}\text { - Los intermediarios hacen de lo suyo con los } \\
\text { productos de la zona. } \\
\text { - No hay comunicación entre instituciones. }\end{array}$ \\
\hline Político & - Apoyo a las instituciones. & $\begin{array}{l}\text { - No existe una decisión política y apoyo } \\
\text { turístico. }\end{array}$ \\
\hline
\end{tabular}




\begin{tabular}{|c|c|c|}
\hline Ambiental & $\begin{array}{l}\text { - Afluencia de turistas nacionales y } \\
\text { extranjeras con la biodiversidad } \\
\text { natural de la Amazonía Ecuatoriana. }\end{array}$ & $\begin{array}{l}\text { - No hay una política adecuada para el manejo } \\
\text { de los desechos sólidos. } \\
\text { - Caza masiva de animales de la zona. }\end{array}$ \\
\hline Cultural & $\begin{array}{l}\text { - Apoyar a la difusión, rescate y } \\
\text { valorización de la danza autóctona, } \\
\text { sus cuentos y leyendas. }\end{array}$ & $\begin{array}{l}\text { - Aculturalización de los pueblos originarios } \\
\text { perdiéndose poco a poco su música, danza e } \\
\text { instrumentos musicales. }\end{array}$ \\
\hline
\end{tabular}

Fuente: Elaboración propia.

\section{EVALUACIÓN DE FACTORES \\ INTERNOS}

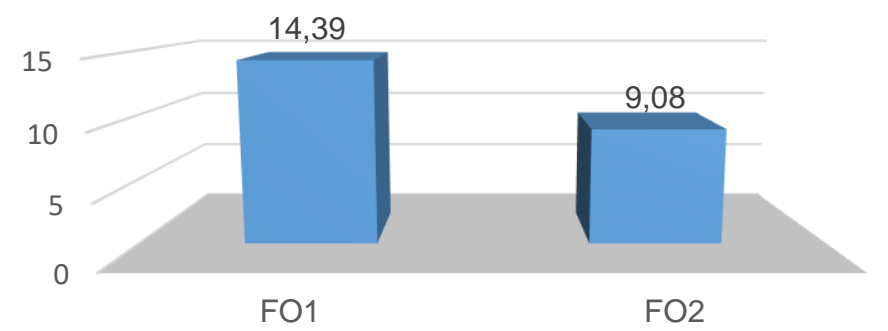

Figura 1. Matriz MEFI (Matriz de evaluación de factores internos). Fuente: Elaboración propia.

Después de haber realizado la matriz de evaluación de análisis interno, de acuerdo a los parámetros de calificación, el presente estudio, está en un promedio media nominal de 2.55; el 2.81 que arrojan los datos es importante mostrar que la academia en el ámbito turístico tiene un nivel superior de fortalezas, pero sin embargo es necesario exponer que las debilidades mantienen un rango importante que hay que afrontar y minimizarlos.

\section{EVALUACIÓN DE FACTORES \\ EXTERNOS}

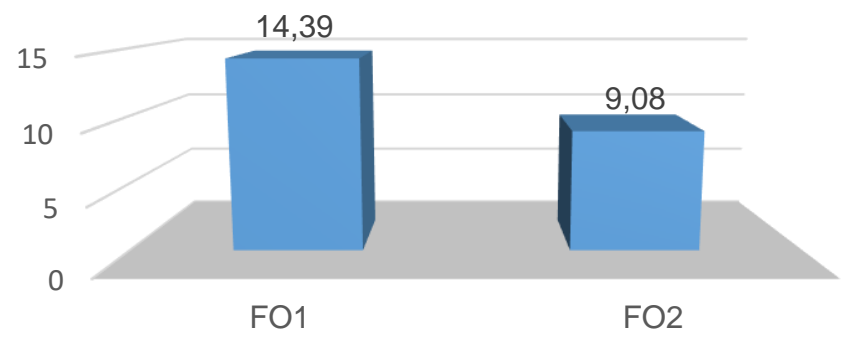

Figura 2. Matriz MEFE (Matriz de evaluación de factores externos). Fuente: Elaboración propia.

Al análisis del entorno exógeno de la Academia en referencia a los graduados de la carrera de turismo, es sin duda un elemento importante; a fin, de saber pertinentemente las oportunidades y amenazas que presenta, que inciden directa e indirectamente en el vivir diario los estudiantes que han escogido la carrera de turismo, y que además son parte de un proceso como oferentes de servicios dentro de la localidad, luego de una lectura crítica de la matriz de evaluación externa, tomando los resultados obtenidos en las ponderaciones de 2.56; es indudable que los graduados posee un número demostrativo que oportunidades en un 1,82 y en un 0,74 en diferencia de las amenazas, que de igual manera está presente en 
cooperación considerable, la academia debe continuar desarrollándose en todo sus ámbitos para el bienestar de los graduados y estudiantes, apoyarse en las oportunidades y disminuir las amenazas en función a las estrategias.

\section{Tabla 13}

Resumen de estrategias de posicionamiento

\begin{tabular}{|c|c|c|}
\hline & FORTALEZAS - F & DEBILIDAD - D \\
\hline FODA & $\begin{array}{l}\text { Buena relación de gobernabilidad } \\
\text { de la academia con las autoridades } \\
\text { locales. } \\
\text { Excelente trabajo entre la empresa } \\
\text { pública y privada. } \\
\text { Ciudadanos organizados. } \\
\text { Formación académica adecuada. } \\
\text { Oferta profesional en turismo. } \\
\text { Formar profesionales en turismo. } \\
\text { Participación con la comunidad. } \\
\text { Conocimientos ampliados en } \\
\text { turismo. } \\
\text { Tecnificación del servicio turístico. }\end{array}$ & $\begin{array}{l}\text { Las autoridades no apoyan a los } \\
\text { proyectos turísticos emblemáticos. } \\
\text { No hay iniciativas locales de las } \\
\text { autoridades para definir al turismo } \\
\text { como prioridad. } \\
\text { Inexistencia de un trabajo seguro. } \\
\text { Falta de un centro de oferta de } \\
\text { trabajo. } \\
\text { La comunidad no cuenta } \\
\text { alcantarillado. } \\
\text { No existe un plan de desarrollo } \\
\text { turístico provincial. } \\
\text { Falta de especialización técnica en } \\
\text { gastronomía, operación en deporte } \\
\text { de aventura. } \\
\text { Baja en liquidez por falta de } \\
\text { efectivo. }\end{array}$ \\
\hline OPORTUNIDAD - 0 & ESTRATEGIAS - FO & ESTRATEGIAS - DO \\
\hline \begin{tabular}{l}
4 \\
\multicolumn{3}{l}{ Contar con un centro educativo de } \\
primera, equipamiento y \\
laboratorios. \\
Contar con un centro de \\
investigación.
\end{tabular} & $\begin{array}{l}\text { Realizar alianzas a través de } \\
\text { convenios con las autoridades } \\
\text { locales (F1, F2, F4, F6, O1, O2, } \\
\text { O6). }\end{array}$ & $\begin{array}{l}\text { Propiciar la inserción laboral de los } \\
\text { graduados de la UEA de la Carrera } \\
\text { de Turismo en el mercado laboral } \\
\text { (F1, F2, F4, F5, F6, F7, F8, F9, O1, } \\
\text { O2, O5). }\end{array}$ \\
\hline
\end{tabular}

con préstamos CFN y BanEcuador.

Programa para la difusión y publicidad de los atractivos.

Apoyo a las instituciones.

Afluencia de turistas nacionales y extranjeros por la biodiversidad natural de la Amazonía Ecuatoriana.

Apoyar a la difusión, rescate y valorización de la danza autóctona, sus cuentos y leyendas.

\section{AMENAZAS - A}

Pérdida de la cultura a través de la migración.

Inseguridad.

Los intermediarios hacen de los suyos en los productos de la zona. No hay comunicación.

No existe una decisión política y apoyo turístico.

No hay una política adecuada para el manejo de los desechos sólidos. Caza masiva de animales de la zona.

Aculturalización de los pueblos perdiéndose poco a poco su música, danza e instrumentos musicales.
Proponer a la UEA la innovación de la malla curricular de la Carrera de Turismo (F4, F5, F6, F8, F9, O1, O4, O6).
Capacitación y preparación de los graduados en implementación de emprendimientos turísticos (F2, F4, F6, F8, F9, O1, O5, O6, O7).

Fuente: Elaboración propia. 
En esta etapa importante, las decisiones que ha arrojado así como la matriz cualitativa de planificación, las estrategias adquiridas en la matriz FODA están comparando con los factores organizacionales y de entorno, los datos críticos de éxito; ocho estrategias logradas en función de los objetivos las puntuaciones más altas corresponden a: FO1 con un valor 14,39 , seguido de DO1 con un valor de 13,23 y de DA1 con un valor de 13,13, FA2 con 12,21, FA1 con 11,06, DO 2 con 9,34, F02 con 9,08, DA2 con 8,62, con estos valores se tomará las decisiones correctas en función a la valoración.

\section{MATRIZ CUALITATIVA DE PLANIFICACIÓN ESTRATÉGICA}

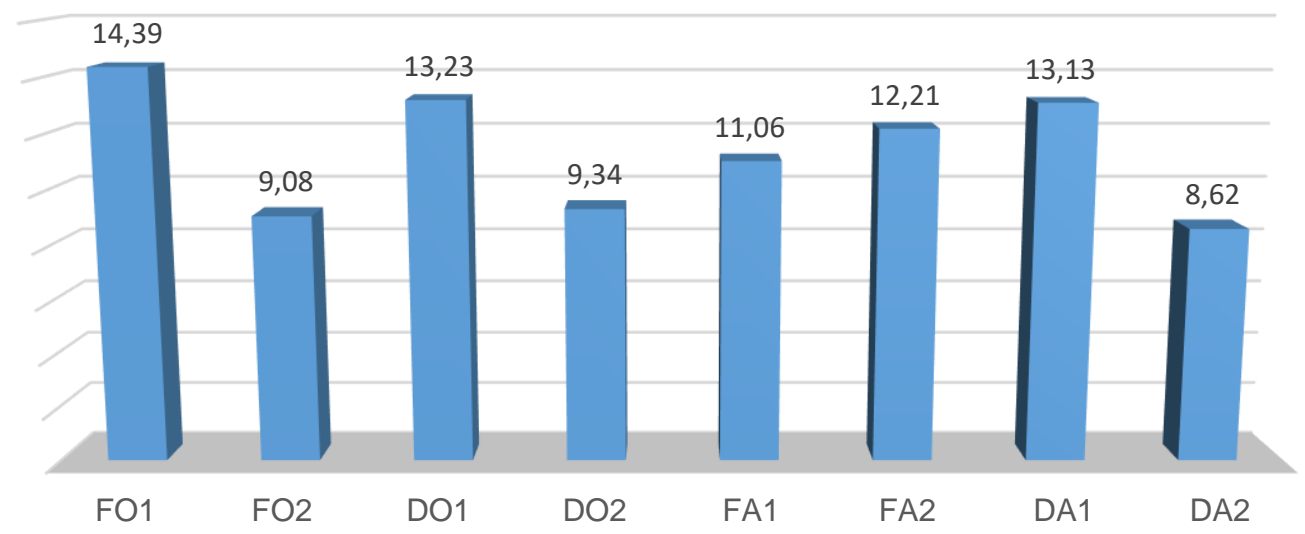

Figura 3. Matriz cualitativa de planificación estratégica. Fuente: Elaboración propia.

\section{Tabla 14}

Líneas Estratégicas

\begin{tabular}{|c|c|c|}
\hline ESTRATEGIAS & VALOR & LÍNEA ESTRATÉGICA \\
\hline FO1 & 14,39 & $\begin{array}{l}\text { Realizar alianzas estratégicas a través de convenios con las autoridades } \\
\text { locales. }\end{array}$ \\
\hline FO2 & 9,08 & $\begin{array}{l}\text { Proponer a la UEA la innovación de la malla curricular de la Carrera de } \\
\text { Turismo. }\end{array}$ \\
\hline D01 & 13,23 & $\begin{array}{l}\text { Propiciar la inserción laboral de los graduados de la UEA de la Carrera de } \\
\text { Turismo en el mercado laboral. }\end{array}$ \\
\hline DO2 & 9,34 & $\begin{array}{l}\text { Capacitación y preparación de los graduados en la implementación de } \\
\text { emprendimientos turísticos. }\end{array}$ \\
\hline FA1 & 11,06 & Propiciar una decisión política de apoyo al turismo desde la Academia. \\
\hline FA2 & 12,21 & $\begin{array}{l}\text { Fomentar mayor vinculación con la comunidad y el apoyo a las } \\
\text { comunidades dedicadas al turismo. }\end{array}$ \\
\hline DA1 & 13,13 & $\begin{array}{l}\text { Propiciar la elaboración de un plan de desarrollo turístico provincial en el } \\
\text { que se considere a la academia y sus estudiantes }\end{array}$ \\
\hline DA2 & 8,62 & Fomentar capacitación en áreas gastronómicas y hoteleras. \\
\hline
\end{tabular}

Fuente: Elaboración propia. 


\section{Tabla 15}

Estrategias para la propuesta

\begin{tabular}{|c|c|c|c|c|}
\hline & STRATEGIAS & $\begin{array}{c}\text { ALIANZAS } \\
\text { ESTRATÉGICAS }\end{array}$ & ACCIONES & PROPÓSITOS \\
\hline 1. & $\begin{array}{lr}\text { Determinar } & \text { alianzas } \\
\text { estratégicas } & \text { entre } \\
\text { actores turísticos con } & \text { cr de } \\
\text { la finalidad } & \text { de } \\
\text { fomentar } & \text { esta } \\
\text { actividad. } & \end{array}$ & $\begin{array}{l}\text { Entre la UEA y las } \\
\text { ONGs, Operadoras } \\
\text { Turísticas. } \\
\text { - Asociaciones de } \\
\text { turismo. } \\
\text { - Entre la UEA y los } \\
\text { GADs cantonales, } \\
\text { parroquiales y } \\
\text { provincial. } \\
\text { Entre la UEA y los } \\
\text { representantes de las } \\
\text { Comunidades } \\
\text { indígenas de la } \\
\text { provincia. }\end{array}$ & 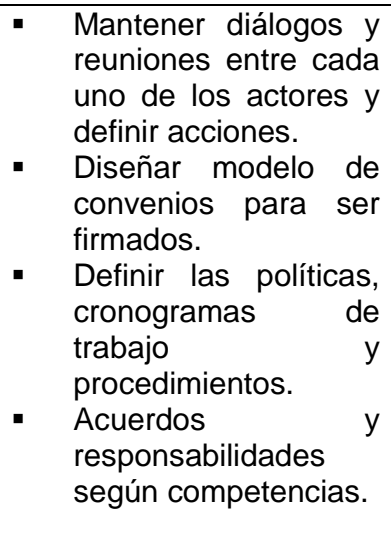 & 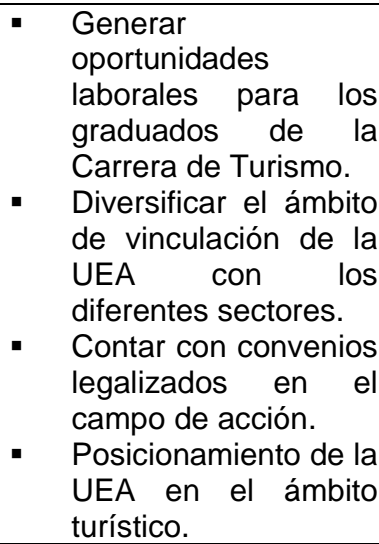 \\
\hline 2. & $\begin{array}{l}\text { Propiciar la inserción } \\
\text { laboral de los } \\
\text { graduados de la UEA } \\
\text { de la Carrera de } \\
\text { Turismo en el } \\
\text { mercado laboral }\end{array}$ & 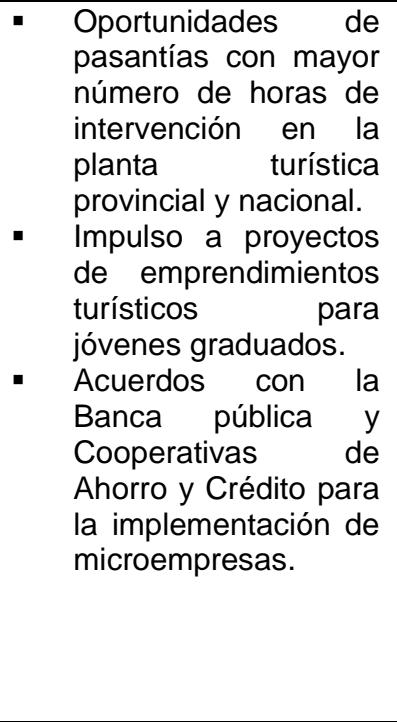 & 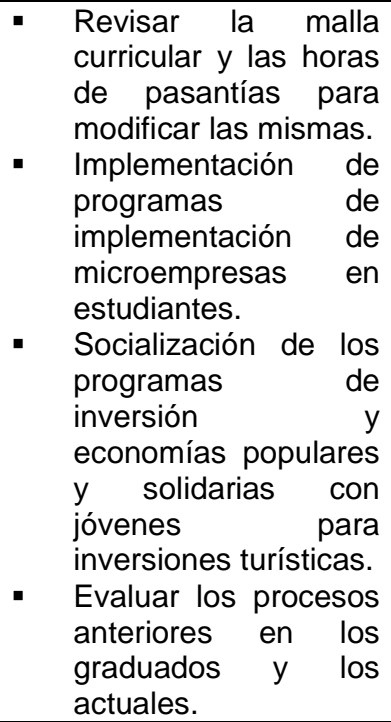 & 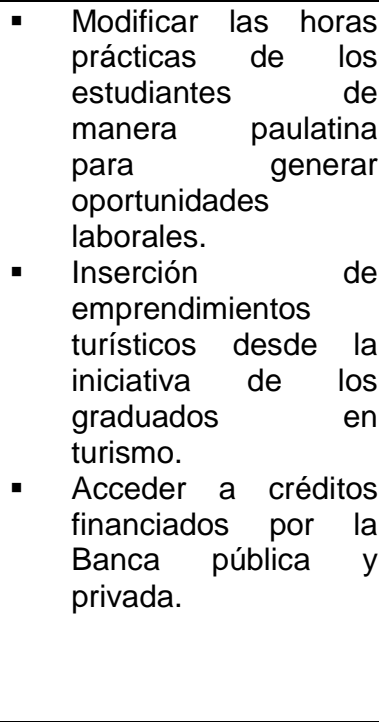 \\
\hline & $\begin{array}{l}\text { 3. Propiciar la } \\
\text { elaboración de un } \\
\text { plan de desarrollo } \\
\text { turístico provincial en } \\
\text { el que se considere a } \\
\text { la academia y sus } \\
\text { estudiantes }\end{array}$ & 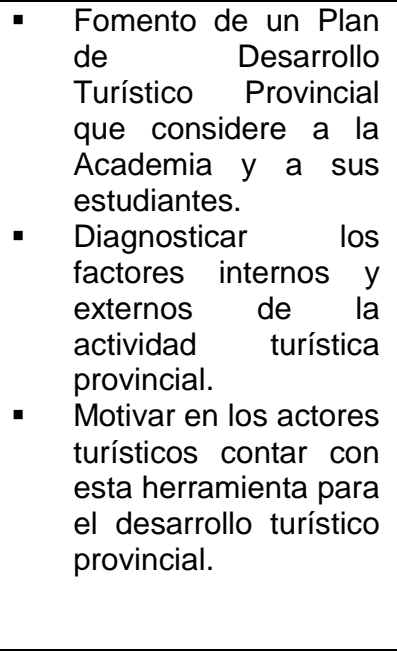 & 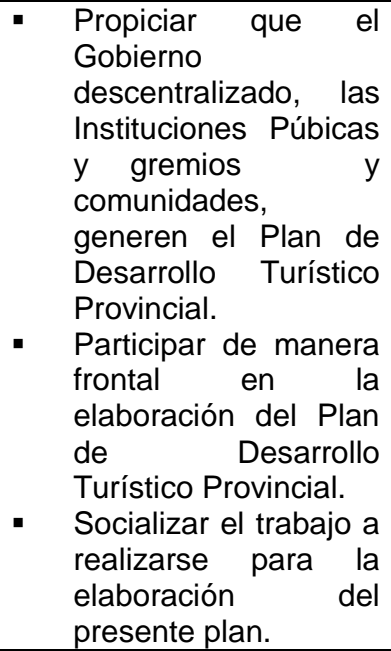 & 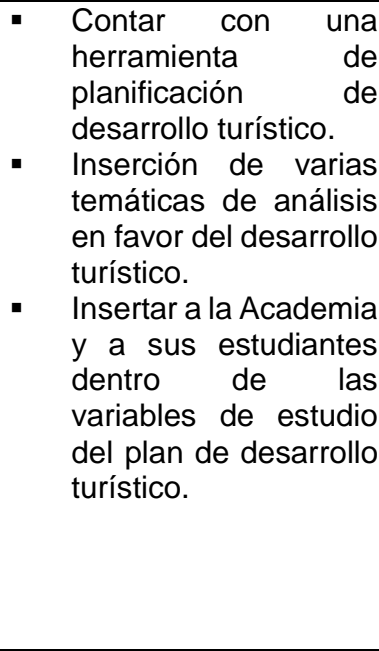 \\
\hline & $\begin{array}{l}\text { 4. Fomentar mayor } \\
\text { vinculación con la } \\
\text { sociedad y el apoyo a } \\
\text { las comunidades } \\
\text { dedicadas al turismo. }\end{array}$ & $\begin{array}{l}\text { Fomento de acuerdos } \\
\text { con la AHOTEP, } \\
\text { CAPTUR, MINTUR y } \\
\text { GADS para realizar } \\
\text { actividades r de } \\
\text { vinculación con la } \\
\text { sociedad. }\end{array}$ & $\begin{array}{l}\text { - } \text { Firmar los acuerdos y } \\
\text { convenios con } \\
\text { AHOTEP, CAPTUR, } \\
\text { MINTUR, GADS. } \\
\text { - Implementación de } \\
\begin{array}{l}\text { programas } \\
\text { vinculación }\end{array} \\
\text { diseñados. }\end{array}$ & $\begin{array}{lrr}\text { Mejora en } & \text { la } \\
\text { generación } & \text { de } \\
\text { instrumentos } & \text { legales } \\
\text { para con convenios o } \\
\text { acuerdos que le } \\
\text { permitan a los } \\
\text { estudiantes } \\
\text { vinculación. }\end{array}$ \\
\hline
\end{tabular}


- Diseño de programas de vinculación en las que se desarrolle las capacidades de los estudiantes de la Carrera de Turismo.

- Motivar en los estudiantes a la generación de mayor vinculación con la comunidad y fomento de sus capacidades.

5. Propiciar una
decisión política de
apoyo al turismo
desde la Academia
a través de una Mesa
Académica y de
Inserción Laboral.

Fomento de acuerdos con la mesa académica que trate temas de actualidad de la realidad de las universidades y los estudiantes.

- Elaboración de un cronograma de trabajo y definición de acuerdos responsables dentro de la mesa.

- Motivar los diálogos de decisión política para apoyos al turismo desde la visión de la mesa académica.

6. Capacitación y preparación de los graduados en la implementación de emprendimientos turísticos.

programas

emprendimientos turísticos a maneras de microempresas turísticas.

- Elaboración de planes de negocios.

- Capacitación intensiva en planes de negocios turísticos.

7. Proponer a la UEA la innovación de la malla curricular de la Carrera de Turismo

\section{Revisión de la malla} curricular en cumplimiento de las horas y temáticas actuales, donde el componente práctico tenga un fondo de tiempo que permita adquirir competencia.

- Elaboración de una propuesta de malla curricular para ser aprobada en el consejo Superior de la UEA.

- Motivar los diálogos de decisión a las autoridades de la UEA.

$\begin{array}{lrll}\begin{array}{l}\text { Motivación } \\ \text { incentivos a } \begin{array}{r}\text { con } \\ \text { los } \\ \text { estudiantes para }\end{array} \\ \text { poder desarrollar } \\ \text { mayor vinculación. }\end{array} & \begin{array}{l}\text { Ampliación de lugares } \\ \text { los programas de } \\ \text { lonculación para } \\ \text { mejorar la experticia } \\ \text { de sus estudiantes. }\end{array} \\ & \begin{array}{l}\text { Acceder al fomento de } \\ \text { capacidades de los } \\ \text { estudiantes para una } \\ \text { mejor vinculación. }\end{array}\end{array}$
convenios en base al cronograma de trabajo de la mesa académica.

- Implementación de programas, acuerdos y responsabilidades de acuerdo a la mesa académica.

- Elaboración de la hoja de ruta para planificar el desempeño de la Mesa de Turismo.

\begin{tabular}{lr}
\multicolumn{3}{l}{ Contar con acuerdos } \\
y convenios de \\
cooperación de la \\
mesa académica. \\
Definición de \\
acuerdos do \\
responsabilidades \\
según competencia. \\
Diálogos \\
permanentes de \\
decisión política para \\
apoyos al turismo \\
desde la visión de la \\
mesa académica.
\end{tabular}

iar con acuerdos (n) .

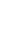
mesa académica.

\begin{tabular}{|c|c|c|c|c|}
\hline $\begin{array}{l}\text { Propuesta de } \\
\text { capacitaciones que } \\
\text { permitan la mejora de } \\
\text { la formación de las } \\
\text { áreas gastronómicas } \\
\text { y hoteleras. }\end{array}$ & = & $\begin{array}{l}\text { Puesta en marcha de } \\
\text { las capacitaciones } \\
\text { que permitan la } \\
\text { mejora } \\
\text { conocimientos a los } \\
\text { graduados. }\end{array}$ & & $\begin{array}{l}\text { Contar con las } \\
\text { propuestas de } \\
\text { capacitación } \\
\text { ejecutable y apegada } \\
\text { a la realidad local. }\end{array}$ \\
\hline
\end{tabular}


- Elaboración de un cronograma de capacitación en la mesa académica y otros espacios.

- Profesionalización de los graduados con temas de gastronomía y de hotelería entre otros.

- Propiciar la conformación de clubes o espacios de desarrollo práctico en áreas turísticas.

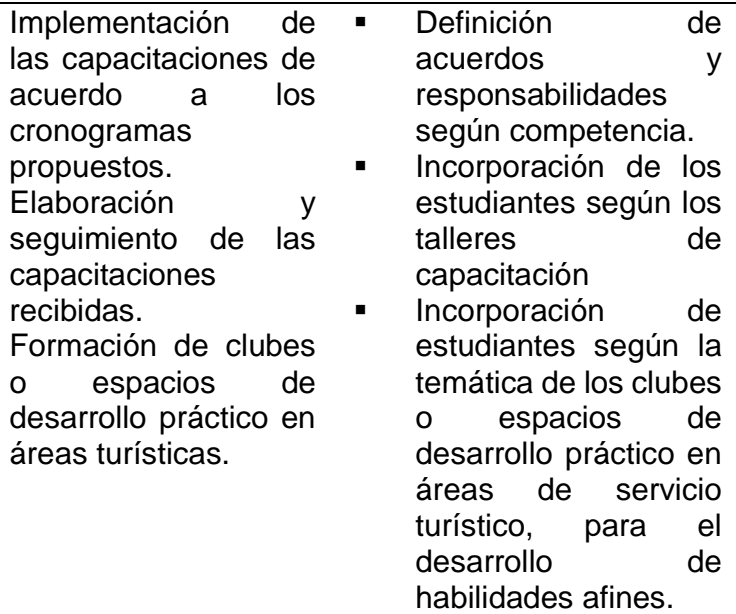

Fuente: Elaboración propia.

\section{DISCUSIÓN DE RESULTADOS}

Los resultados de este estudio muestran que es necesario poseer una formación integral en los graduados a fin de hacer frente a las necesidades del mercado laboral, evitar el desempleo y promover la estabilidad personal y social de cada individuo. Muchos son los factores que aportan a esta formación, cada uno debe permitir el acceso laboral y posicionamiento en las empresas públicas o privadas. Se identifica claramente la necesidad del diseño de estrategias de posicionamiento, las cuales aportarán en la inserción laboral de los graduados de la carrera de turismo, existe una estrecha y evidente relación en estos.

Se plantea en el documento la importancia y el aporte positivo de las estrategias de posicionamiento para la inserción laboral; queda claro y se concuerda en análisis con grupos focales que existe gran oferta de los graduados en la carrera de turismo, esta oferta es muy alta en relación a la capacidad de la demanda, principalmente en la provincia; a más de ello, en la rama de turismo se presentan problemas económicos, lo cual no genera mayores oportunidades de empleo, el turismo cada vez cuenta con menor presencia y por ende la oferta laboral es reducida.

Se identifica claramente que la provincia cuenta con actividades relacionadas al turismo, existen 270 establecimientos que de una u otra forma pueden brindar oportunidades laborales, sin embargo, el 30\% de los graduados no tiene un trabajo, el $47 \%$ ha tardado de 1 a 4 años para obtener un empleo; las cifras son altas; a esto se suma que estos puestos de trabajo no están relacionados a la formación profesional, el 75\% desempeñan funciones fuera del área de turismo.

Se ha encontrado que existen factores que inciden en la ausencia de un puesto de trabajo, en su mayoría coinciden que las pocas horas de prácticas preprofesionales, las reducidas 
plazas de trabajo y la competencia desleal, han influido en que no se logre este posicionamiento laboral.

Estudios adicionales plantean la relación en la oferta y demanda laboral en el área de turismo, mostrando que existe una gran brecha entre la preparación académica y las necesidades del mercado laboral; además, se identifica la dificultad para una inserción laboral rápida y satisfactoria; para lo cual se han planteado propuestas que permitan la inserción de los egresados de la universidad, como una mayor preparación curricular enfocando en las necesidades del mundo actual, desarrollo de pasantías y prácticas para generar contactos con empresas, impulso al área turística para generar alternativas de trabajo; se coincide que uno de los problemas para la inserción laboral es la escasa oferta de empleo y la saturación del mercado. (Benítez, 2014).

Frente a todas estas problemáticas, se ha planteado las estrategias de posicionamiento, con énfasis en el aumento de experiencia laboral, mayores horas de prácticas preprofesionales y el establecimiento de alianzas estratégicas para la inserción en las empresas relacionadas al turismo.

Estas estrategias permitirán incrementar las oportunidades laborales diversificando la actividad turística y la oferta laboral, para lo cual fue necesario el análisis FODA, cuyos resultados relevantes son que se deben realizar alianzas estratégicas y convenios con autoridades locales, propuesta de innovación en la malla curricular de la carrera de turismo, mayor capacitación en inserción laboral e implementación de emprendimientos turísticos, apoyar al sector turístico mediante mayor vinculación con las comunidades, elaboración de planes de desarrollo turístico.

Se manifiesta en otros estudios relacionados a la inserción laboral en el área de turismo que además de estrategias mencionadas anteriormente, se destacan también otras, tales como el impulso al uso y aprendizaje de herramientas informáticas, el dominio del idioma inglés, el fomentar el desarrollo del turismo local, la creación de un colegio que regule las actividades de los graduados; concluyen que el mejorar las condiciones laborales es tarea de todos los actores involucrados, debe haber una interacción para lograr resolver las dificultades de inserción laboral.

En conclusión, este estudio muestra la importancia de las estrategias de posicionamiento para la inserción laboral, se requiere considerar la ejecución de cada una de ellas, para promover el aumento de probabilidades en la adquisición de una plaza laboral. 


\section{CONCLUSIONES}

Para la gran parte de estudiantes en un $20 \%$ los factores de posicionamiento que influencias en la inserción laboral de los graduados de la Carrera de Turismo es las pocas horas de práctica pre-profesionales que deben incrementarse, las reducidas plazas de trabajo actual, en un $18,75 \%$ que relacionan con el comportamiento de la demanda turística, la competencia desleal existente en un $17,50 \%$, la falta de experiencia en un 12,50 que le permita al estudiante generar una empresa turística, el 12,50 dice que es la falta de destrezas y facilidad para los estudiantes para crear sus propias empresa; seguido de una inseguridad generalizada en un $8,75 \%$ y por último consideran que es deficiente formación académica en un $8,75 \%$.

Se diseñó estrategias de posicionamiento como aporte en la inserción laboral de los graduados. Es así que, con el levantamiento de un diagnóstico, toma de criterios y opiniones de quienes tienen una trayectoria en el área turística se plantearon acciones que conlleven a propósitos eficaces que mejoren la situación actual de los graduados de la UEA, 2009 - 2016.

\section{REFERENCIAS BIBLIOGRÁFICAS}

Armengol, M., y Casas, M. (2005). Nueva universidad ante la sociedad del conocimiento. (pp. 1-18).

Abdalá, E., Jacinto, C., y Solla, A. (2005). La inclusión laboral de los jóvenes: entre la desesperanza y la construcción colectiva. Montevideo: CINTERFOR - OIT.

Barney, J., y Clark, D. (2007). Resource based theory: Creating and sustaining competitive advantage. Oxford: Oxford University Press.

Bañuls, A. L. (2009). Human capital and its role in the tourist sector: some reflections and proposals. (pp. 243-248).

Benitez, G. (2014). La inserción laboral de los graduados en turismo de la universidad nacional del sur en el mercado laboral de agencias de viajes en Bahía Blanca. Universidad Nacional del Sur.

Bozu, Z., y Canto, P. (2009). El profesorado universitario en la sociedad del conocimiento: competencias profesionales docentes. Revista de Formación e Innovación Educativa Universitaria. (pp. 87-97).

Castillo, M. (2017). Epistemología del Turismo. (pp. 133-156).

Castillo, M. (2007). La investigación y epistemología del turismo: aportes y retos. Revista Hospitalidades. (pp. 79-95).

CIESPAL. (2007). Cohesión Social: Inclusión y sentido de pertinencia en América latina y el Caribe. Santiago: LC/G Rev. 
Cuevas, L., Herrera, A., \& Vargas, R. (2011). La profesión turística: ejes de explicación en su relación con la formación académica. Revista de Educación Superior. (pp. 160).

Cuevas, J. L. M. (2011). La profesión turística: ejes de explicación en su relación con la formación académica.

Chiavenato, I. (2010). Innovaciones de la administración tendencias y estrategias de los nuevos paradigmas. México, D.F. México. Editorial Programas educativas S.A. de C.V.

Damm, M. (1998). Educación Profesional en turismo. Gestión Turística. (pp. 23-37).

Demajorovic, J., Aledo, A., Landi, B. \& Mantovani, A. (2011). Complejos turísticos residenciales: análisis del crecimiento del turismo residencial en el mediterráneo español y en el litoral nordestino (Brasil) y su impacto socio ambiental.

Gómez, V. (2009). Desempeño Laboral del Licenciado en Turismo de la Universidad de Oriente. Valdivia: GEST- TUR.

Guevara, R. (2006). Estudios multidisciplinarios en turismo. Estudios Multidisciplinarios En Turismo. (pp. 293).

Hernández, C., Martín, C., Jiménez, A., Domínguez, C., \& Bermúdez, I. (2010). Tourism Training in Spain: Past, Present and Future in the New European Higher Education Area. (pp. 257-261).

Hernández, S., \& Palafox, R. (2012). Administración teoría, procesos, áreas fundamentales y estrategias para la competencia. México, D.F. México. Editorial Offset Max S.A de C.V.

Hernández, J. (2011). Componente Laboral en la Carrera de Estudios. (pp. 1-9). Recuperado de http://www.sociedadelainformacion.com/25/habilidades.pdf

Hirsch, J. (2001). ¿Qué es la globalización? Globalización, Capital y Estado, (pp. 95-105).

Heckman, J. (2006). La Educación en los Informes internacionales. México: Trillas.

Jafari, J. (2005). The sceintification of tourism: Contribuciones a la Economía. Recuperado de https://www.cabdirect.org/cabdirect/abstract/20033003504

Jafari, J. (2005). El turismo como disciplina científica. Política y Sociedad. (pp. 39-56). Recuperado de https://doi.org/10.5209/POSO.24139

Lillo, A., Ramón, A., \& Sevilla, M. (2007). El capital humano como factor estratégico para la competitividad del sector turístico. Cuadernos de Turismo. (pp. 47-69). 
Martín de la Rosa, B. (2003). Nuevos turistas en busca de un nuevo producto: el patrimonio cultural. Pasos. (pp. 155-160). Recuperado de https://doi.org/10.25145/j.pasos.2003.01.015

Ministerio de Turismo. (2002). Ley de Turismo del Ecuador. Quito: Mintur.

Ministerio de Turismo. (2004). Reglamento General de aplicación la Ley de Turismo. Quito.

Mora, J. (2004). La necesidad de cambio educativo para la sociedad del conocimiento. Revista Iberoamericana de Educación. (pp. 13-37).

Morales, P. (2012). Estadística aplicada a las Ciencias Sociales: Tamaño necesario de la muestra.

Recuperado

de

Www.up".es/personal/peter/investigacion/Tama\%F1oMuestra.pfd

López, J., \& Montero, A. (2005). Trabajo, Empleo y Desempeño en la Teoría Económica: La Nueva Ortodoxia. Málaga: Universidad de Málaga.

Oficina de Gestión y Promoción Turística de Pastaza (2018). MIN-TURISMO. Puyo, Pastaza, Ecuador.

Organización Internacional del Trabajo. (2004). Por una globalización justa. El papel de la OIT - Sobre la Dimensión Social de la Globalización. Ginebra: OIT. (pp. 18).

Organización Mundial del Trabajo. (2006). La Relación de Trabajo. Oficina de Ginebra Conferencia Internacional del Trabajo. Ginebra: OIT. (pp. 18-19).

Organización Mundial del Turismo. (2016). Glosario de Términos. Madrid: OMT, UNTWO.

Otero, A. (2007). La importancia de la visión del territorio para la construcción de desarrollo competitivo de los destinos turísticos. Cuadernos de Turismo. Murcia. (pp. 91-104).

Plaza, A., Andrade, P., \& Marcillo, J. (2016). El papel de la Universidad en el desarrollo productivo. Guayaquil: Universidad de Guayaquil.

Plan de la Carrera de Turismo (2009), Universidad Estatal Amazónica. Proyecto de la Carrera de Turismo aprobado por el ExCONESUP.

Pérez, V., \& Rodríguez, J. (2002). El perfil del profesor mediador. Madrid: Taurus-

Grupo Santillana.

Porter, E., \& Kramer, M. (2006). Estrategia y sociedad. Harvard Business Review. (pp. 3-15).

Rentería, E., \& Enríquez, Á. (2006). ¿Usted mismo S.A.? o el posicionamiento profesional en el mercado de trabajo. Reflexiones desde el marketing y el comportamiento del consumidor. Psicología Desde El Caribe. (pp. 139-160).

Robles, P., \& Rojas, M. (2015). La validación por juicio de expertos: dos investigaciones cualitativas en Lingüística aplicada. 
Rojas, A. (2012). Situación Laboral del profesional Titulado en la carrera de Turismo de la UMSA. La Paz: UMSA.

Santiago, P., Tremblay, K., Basri, E., \& Arnal, E. (2008). Strengthening ties with the labour market. Paris: OCDE.

Sancho, A. (2008). Introducción al Turismo. Recuperado de file://C:/Users/usuario/Documents/Maestria UEA/Proyecto de tesis/Tema turismoUEA/Bibliografia/Introduccion_al_Turismo_OMT_Organizacion.pdf

SEDETUR (2017). Indicadores turísticos. Recuperado de http://sedetur.qroo.gob.mx/estadisticas/indicadores/2017/Indicadores Tur - enero diciembre 2016.pdf

Secretaría Académica (2018). Universidad Estatal Amazónica. Puyo. Ecuador.

Tobón, S. (2008). La formación basada en competencias en la educación superior: el enfoque complejo. México: Universidad Autónoma de Guadalajara. Recuperado de http://www.conalepfresnillo.com/images/stories/conalep/Formación basada en competencias. Sergio Tobón.pdf

Toselli, C. (2006). Algunas reflexiones sobre el turismo cultural. (pp. 175-182).

Vidal, F., \& Ortega, E. (2003). De los recursos a los sujetos: análisis de micropolíticas de inserción laboral en jóvenes en España. Madrid: INJUVE.

Weller, J. (2005). Problemas de empleo, tendencias y políticas para mejorar la inserción laboral. Santiago: CEPAL.

Wright, P., \& Boswell, W. (2002). Desegragating HRM: A review and synthesis of micro and macro human resource management research. México: Journal of Management. 